\title{
A Model of Rossby Waves Linked to Submonthly Convection over the Eastern Tropical Pacific
}

\author{
ADRIAN J. MATTHEWS \\ Cooperative Research Centre for Southern Hemisphere Meteorology, Monash University, Melbourne, Australia \\ GEORGE N. KILADIS \\ NOAA Aeronomy Laboratory, Boulder, Colorado
}

(Manuscript received 29 September 1999, in final form 20 March 2000)

\begin{abstract}
Equatorward-propagating wave trains in the upper troposphere are observed to be associated with deep convection over the eastern tropical Pacific on the submonthly timescale during northern winter. The convection occurs in the regions of ascent and reduced static stability ahead of cyclonic anomalies in the wave train. In this study an atmospheric primitive equation model is used to examine the roles of the dry wave dynamics and the diabatic heating associated with the convection.

Many features of a dry integration initialized with a localized wave train in the African-Asian jet on a threedimensional climatological basic state quantitatively agree with the observations, including the zonal wavenumber 6-7 scale of the waves, the time period of approximately 12 days, and the cross-equatorial Rossby wave propagation over the eastern Pacific. There is ascent and reduced static stability ahead of the cyclonic anomalies, consistent with the interpretation that the waves force the convection. The spatial scale of the waves appears to be set by the basic state; baroclinic growth upstream in the Asian jet favors waves with zonal wavenumber 6. On reaching the Pacific sector, lower-wavenumber components of the wave train are not refracted so strongly equatorward, while higher-wavenumber components are advected quickly along the Pacific jet before they can propagate equatorward. Once over the Pacific, the wave train approximately obeys barotropic Rossby wave dynamics.

The observed lower-tropospheric anomalies include an equatorial Rossby wave that propagates westward from the region of cross-equatorial wave propagation and tropical convection. However, this equatorial Rossby wave is not forced directly by the dry equatorward-propagating wave train but appears in a separate integration as a forced response to the observed diabatic heating associated with the tropical convection.
\end{abstract}

\section{Introduction}

During northern winter and spring, mean westerly flow extends from the midlatitudes to the equator in the upper troposphere over the eastern Pacific. In theory, this westerly duct should allow barotropic Rossby waves to disperse across the equator (Webster and Holton 1982; Hoskins and Ambrizzi 1993), and observational studies support this scenario (Kiladis and Weickmann 1992a,b, 1997; Hsu and Lin 1992; Tomas and Webster 1994). The equatorward-propagating waves modulate deep convection in the intertropical convergence zone (ITCZ) such that enhanced convection occurs in the region of deep ascent and reduced static stability ahead of the upper-tropospheric troughs (Kiladis 1998). In the

Corresponding author address: Dr. Adrian Matthews, School of Environmental Sciences, University of East Anglia, Norwich, NR4 7TJ, United Kingdom.

E-mail: a.j.matthews@uea.ac.uk lower troposphere, equatorial Rossby wave structures are also observed to propagate westward along the equator from the region of midlatitude Rossby wave incursion and enhanced ITCZ convection.

These transient waves and their associated convection, which have a mean period of 12 days, interact with other, lower-frequency phenomena over the Pacific such as the Madden-Julian oscillation and El Niño-Southern Oscillation (Matthews and Kiladis 1999a,b). The poleward momentum flux (and equatorward E-P flux) of the equatorward-propagating waves is a major component of the regional momentum budget (Kiladis and Feldstein 1994), and over $25 \%$ of the submonthly convective variance within the ITCZ in this region can be accounted for by the equatorward-propagating waves (Matthews and Kiladis 1999b). Therefore, an understanding of the factors that control their dynamics is important for climate studies. Although the transient waves and convection can be simulated well by a general circulation model (Slingo 1998), it is difficult to identify the rel- 
evant mechanisms in such comprehensive nonlinear models.

In this study, the observed equatorward propagation of transient wave activity over the tropical eastern $\mathrm{Pa}$ cific and the forcing of deep convection in the ITCZ are further examined with some idealized experiments using a primitive equation model of the atmosphere. The source of the wave activity, the propagation characteristics of the waves and their ability to induce deep ascent and instability in the ITCZ region and trigger convection, and the possible forcing of equatorially trapped wave structures are of particular interest. The effects of the dry wave dynamics can also be separated from those of the latent heating associated with the deep convection.

\section{Observations}

The observed structure of the equatorward-propagating waves and their associated convection is briefly described. Figure 1 shows a sequence of lagged-regression maps of outgoing longwave radiation (OLR) anomalies and upper- and lower-tropospheric streamfunction and divergence anomalies associated with an enhancement of convection (a negative OLR anomaly) over the base region $5^{\circ}-15^{\circ} \mathrm{N}, 150^{\circ}-140^{\circ} \mathrm{W}$ in the eastern Pacific ITCZ during December-January-February (DJF). The OLR data were obtained from National Oceanic and Atmospheric Administration (NOAA) polarorbiting satellites (Liebmann and Smith 1996) and the circulation data from the National Centers for Environmental Prediction-National Center for Atmospheric Research (NCEP-NCAR) reanalyses (Kalnay et al. 1996). All data were passed through a 6-30-day bandpass Lanczos filter prior to analysis. The reader should refer to Kiladis (1998, hereafter K98) for a full description of the regression technique and interpretation of the results.

To summarize, an upper-tropospheric wave train propagates southeastward from the Asian-Pacific jet exit 4 days prior to the minimum in OLR (day -4; Fig. 1a) and across the equator into the Southern Hemisphere by day +2 (Fig. 1d) along a path that approximates a great circle. ${ }^{1}$ Both southeastward phase propagation (movement of individual highs and lows) and energy propagation or dispersion (development of new centers ahead of the wave train and decay of old centers behind) can be seen. Upper-tropospheric divergence anomalies are located in the poleward flow ahead of the cyclonic anomalies, and convergence anomalies are situated in the equatorward flow behind the cyclonic anomalies.

\footnotetext{
${ }^{1}$ The propagation path of a barotropic Rossby wave on a superrotating basic state is a great circle (Hoskins and Karoly 1981). Although the observed basic state is much more complex than a simple super rotation and factors other than barotropic Rossby wave dynamics cannot be neglected, the observed propagation path is still approximately a great circle.
}

Negative OLR anomalies, which are indicative of high cloud tops and enhanced tropical convection, are collocated with the upper-tropospheric divergence anomalies; the negative OLR anomaly over the base region peaks on day 0 .

In the lower troposphere (Figs. 1e-h) the extratropical flow features tend to be to the east of those aloft, indicative of the westward tilt with height of baroclinic disturbances. Lower-tropospheric divergence anomalies tend to be of the opposite sign to their upper-tropospheric counterparts indicating deep vertical motion extending throughout the troposphere. An equatorial Rossby wave structure can be seen in, for example, the pair of lower-tropospheric cyclonic anomalies either side of the equator at $160^{\circ} \mathrm{W}$ on day 0 (Fig. $1 \mathrm{~g}$ ). These observed anomalies are discussed in greater detail with reference to the model integrations later.

\section{Dry wave dynamics}

\section{a. The model}

The model used in this study is the global spectral primitive equation model of Hoskins and Simmons (1975). A detailed description of the model as used here can be found in Matthews and Kiladis (1999b). It is run at T42 horizontal resolution with 12 vertical levels. The model is linearized about a three-dimensional climatological mean 1979/80-1994/95 DJF basic state. Newtonian cooling, a "boundary-layer" drag, and $\nabla^{6}$ hyperdiffusion are applied to the anomalous fields.

\section{b. Initial perturbation}

The observed fields in section 2 suggest that the transient ITCZ convection over the eastern Pacific is forced or initiated by equatorward-propagating waves. The waves appear to accomplish this by decreasing the static stability of the atmosphere by midtropospheric cold advection and adiabatic cooling from ascent (K98). However, the latent heating associated with the resulting deep convection would also alter the local temperature structure, and it is difficult to separate the effects of the wave dynamics from the convection. A general circulation model study by Slingo (1998) also found that transient convection was modulated by equatorward-propagating waves, but the same causality problem applies there, too.

Therefore, an initial value integration is performed with the primitive equation model. As there is no representation of convection in the model, the ability of dry wave dynamics to create conditions favorable for convection over the ITCZ region can be assessed. The source region for the wave activity can also be examined. Observations suggest that the wave activity originates within the African-Asian jet system and has a zonal wavenumber of approximately 6 (Meehl et al. 1996). 
(a) Day -4

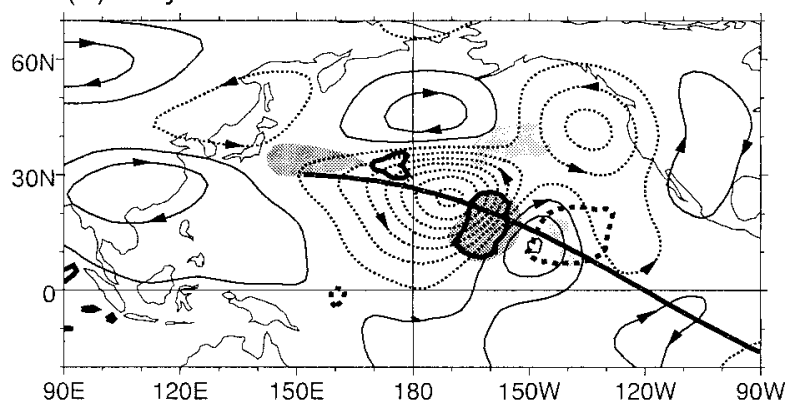

(b) Day -2

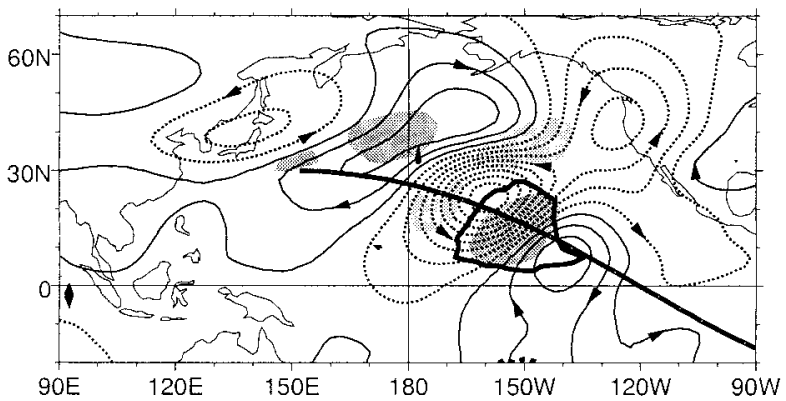

(c) Day 0

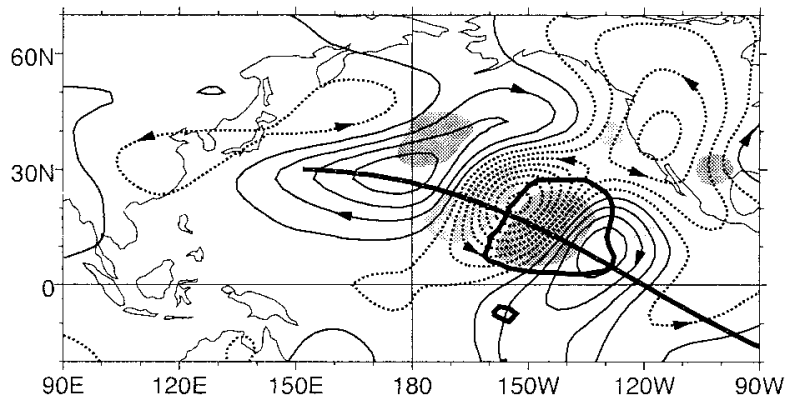

(d) Day +2

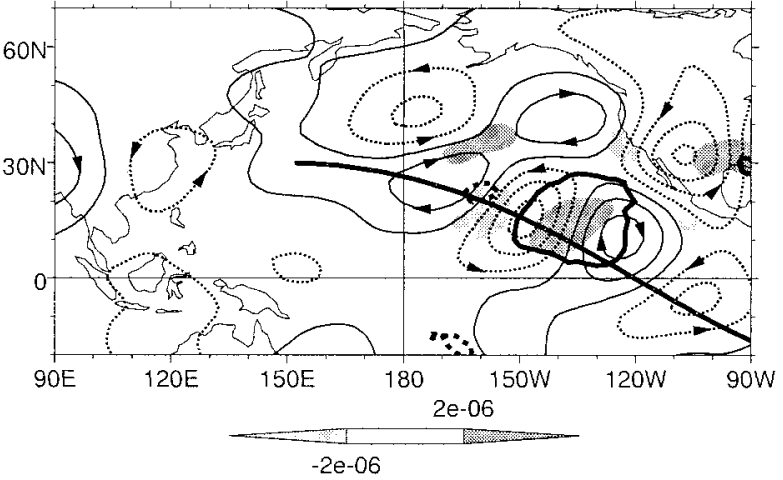

(e) Day -4

\section{$850 \mathrm{hPa}$}

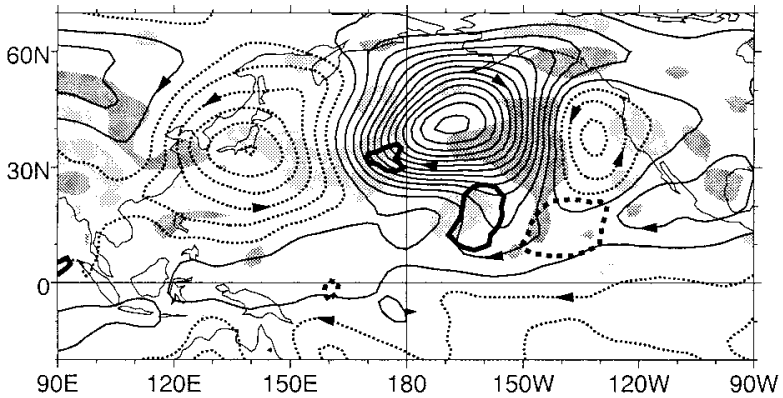

(f) Day -2

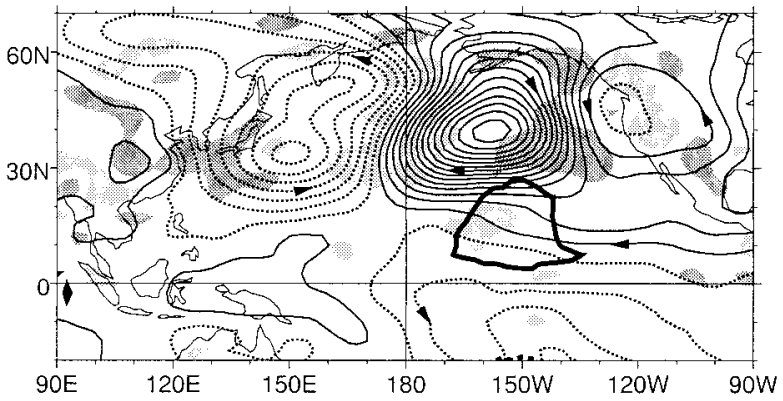

(g) Day 0

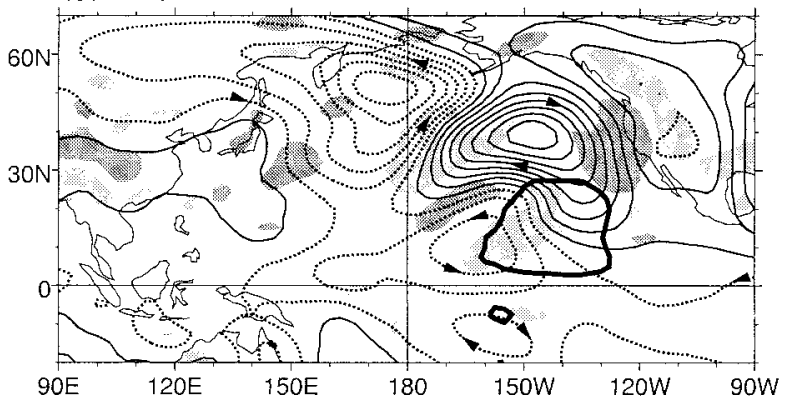

(h) Day +2

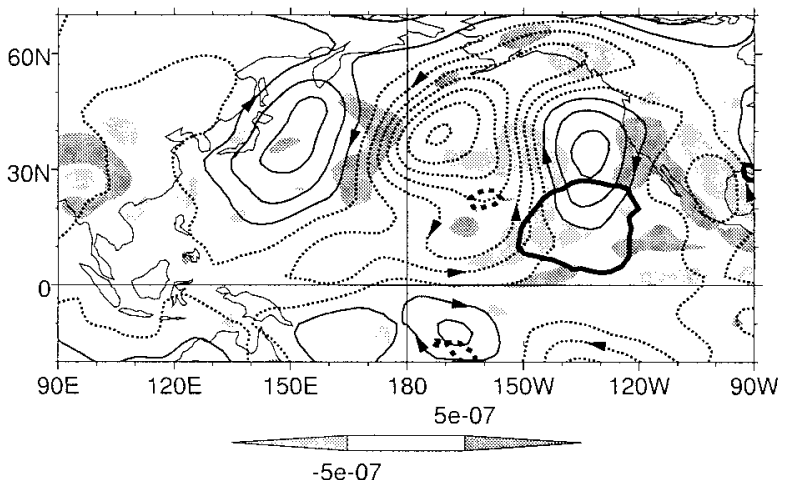

FIG. 1. The 6-30-day OLR, streamfunction and divergence perturbations associated with a $-40 \mathrm{~W} \mathrm{~m}^{-2}$ deviation in OLR in the base region $5^{\circ}-15^{\circ} \mathrm{N}, 150^{\circ}-140^{\circ} \mathrm{W}$ during DJF $1979 / 80-1994 / 95$ from day -4 to day +2 . OLR has a thick solid (dotted) contour at $-10(+10)$ $\mathrm{W} \mathrm{m}{ }^{-2}$. The $200-\mathrm{hPa}$ fields on (a) day -4 , (b) day -2 , (c) day 0 , (d) day +2 ; streamfunction contour interval is $2 \times 10^{6} \mathrm{~m}^{2} \mathrm{~s}^{-1}$ (first positive contour is at $\left.1 \times 10^{6} \mathrm{~m}^{2} \mathrm{~s}^{-1}\right)$. A great circle approximating the path of the wave train is shown by the thick line. The 850-hPa fields on (e) day -4 , (f) day -2 , (g) day 0 , (h) day +2 ; streamfunction contour interval is $0.5 \times 10^{6} \mathrm{~m}^{2} \mathrm{~s}^{-1}$ (first positive contour is at $0.25 \times 10^{6} \mathrm{~m}^{2} \mathrm{~s}^{-1}$ ). The arrows show the circulation direction along the streamfunction contours. Negative streamfunction contours are dotted and divergence shading is shown by the legends. 


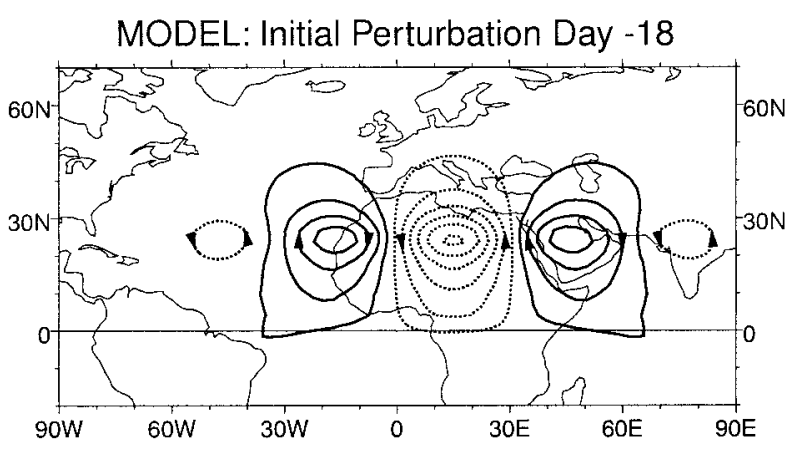

FIG. 2. The 200-hPa streamfunction of the initial perturbation in the African-Asian jet. Conventions are as in Fig. 1.

A localized zonal wavenumber 6 vorticity perturbation in the region of the African-Asian jet and a temperature perturbation in geostrophic balance are created. The perturbations are confined to the upper troposphere above $500 \mathrm{hPa}$. The combined vorticity-temperature perturbation is further balanced using the iterative method of Hoskins and Simmons (1975) to produce a perturbation with zero divergence tendency in a resting atmosphere. This initial perturbation (Fig. 2) is then superimposed onto the three-dimensional basic state and the model integrated forward in time as an initial value problem. As the perturbation is not perfectly balanced, a period of several days' further balancing by inertiogravity wave adjustment within the model then follows until a quasigeostrophically balanced wave train is established in the Asian jet.

\section{c. Horizontal structure}

Figure 3 shows the upper- and lower-tropospheric streamfunction and divergence anomalies over the $\mathrm{Pa}$ cific region from the initial value integration. The start of the integration is denoted as day -18 , as on the 18th day (day 0) of the integration the upper-tropospheric anomalies over the Pacific ITCZ region (Fig. 3c) closely resemble the day 0 anomalies from the observations (Fig. 1c). The integration is linear and the arbitrary amplitude of the model anomalies has been scaled such that the strength of the cyclonic anomaly at $20^{\circ} \mathrm{N}$, $160^{\circ} \mathrm{W}$ on day 0 is $16 \times 10^{6} \mathrm{~m}^{2} \mathrm{~s}^{-1}$, the same as in the observations. Hence, the model anomalies in Fig. 3 can be compared directly with the corresponding observed anomalies in Fig. 1.

By day -4 of the integration there is a balanced wave train in the Asian-Pacific jet (Fig. 3a) that shows many similarities to the observed circulation 4 days before convection peaks over the ITCZ (Fig. 1a), with a cyclonic anomaly near the date line and an anticyclonic anomaly upstream near $120^{\circ} \mathrm{E}$. Over the next few days the model wave train shows southeastward phase propagation as the cyclonic anomaly moves to $20^{\circ} \mathrm{N}, 160^{\circ} \mathrm{W}$ by day 0 (Fig. $3 \mathrm{c}$ ). Cross-equatorial energy propagation is also seen with a new positive streamfunction anomaly developing to the southeast at $10^{\circ} \mathrm{N}, 150^{\circ} \mathrm{W}$ on day -2 (Fig. 3b), and then a new negative streamfunction anomaly develops at $10^{\circ} \mathrm{S}, 110^{\circ} \mathrm{W}$ on day +2 (Fig. 3d). These features are seen in the observations (Figs. 1a-d) although the observed wave train also weakens with time at its upstream (western) end, whereas the model wave train grows everywhere. Upper-tropospheric divergence (convergence) anomalies are located ahead of the cyclonic (anticyclonic) anomalies in the model wave train, in agreement with the observations. In addition to the cross-equatorial propagation approximately along the great-circle path, another wave train propagates along the North American jet in both the model and observations.

Although the initial perturbation in the African-Asian jet has a dominant zonal wavenumber 6 structure, it is a localized wave packet and has power at other zonal wavenumbers. Subsequent dispersion of this wave packet and development within the three-dimensional basic state results in a wave train over the Pacific on day 0 (Fig. 3c) that is clearly more complex than a purely zonal wavenumber 6 perturbation.

The $850-\mathrm{hPa}$ model anomalies (Figs. 3e-h) are in qualitative agreement with the observations in the middle latitudes, at least in terms of location although the model amplitudes are much larger than the observations. The westward tilt with height of the anomalies is indicative of the baroclinic instability in the Asian-Pacific jet that is responsible for the growth of the anomalies between day -4 and day +2 . However, the tropical 850 $\mathrm{hPa}$ model anomalies are very weak. On day 0 there is cyclonically curved flow in the Tropics near the date line (Fig. 3g), but there are no closed streamfunction contours, and there are no anomalies at all in the Southern Hemisphere. Therefore it seems that the equatorial Rossby wave that is present in the observations (Fig. $1 \mathrm{~g}$ ) is not excited by the dry wave train in the model. The possible role of the latent heating associated with the ITCZ convection in forcing the equatorial Rossby wave is examined in section 6 .

\section{d. Vertical structure}

A vertical section of anomalous potential vorticity (PV) along the great-circle propagation path on day 0 of the integration is shown in Fig. 4a. At the $200-\mathrm{hPa}$ level the positive (negative) PV anomalies correspond to the negative (positive) 200-hPa streamfunction anomalies in Fig. 3c. The PV anomalies have maximum amplitude in the lower stratosphere and upper troposphere and extend to near the surface in the extratropics. As the wave train moves into the region of mean lowertropospheric easterly winds in the Tropics the PV anomalies become vertically constrained to the upper troposphere, which is consistent with observations and Rossby wave theory (K98; Tomas and Webster 1994). The PV anomalies exhibit a poleward and westward tilt with height above the 100-hPa level indicating equa- 
(a) Day -4

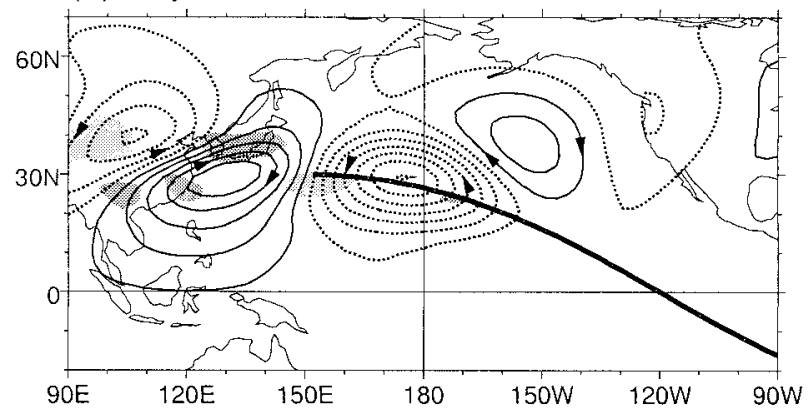

(b) Day -2

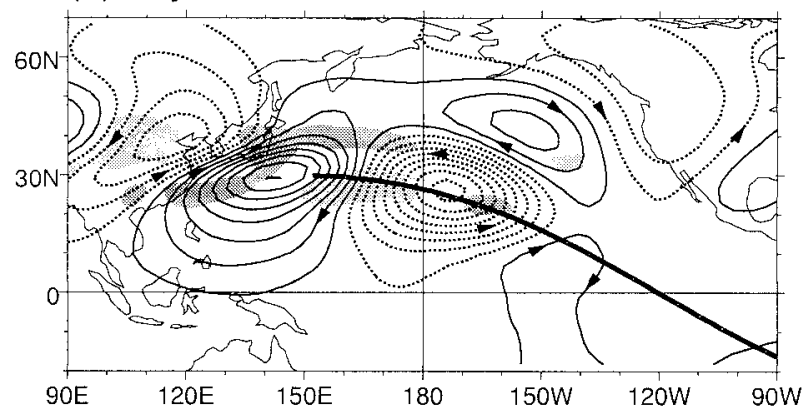

(c) Day 0

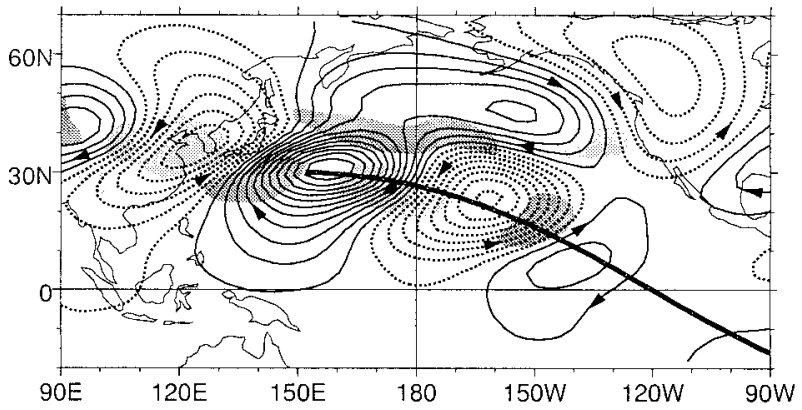

(d) Day +2

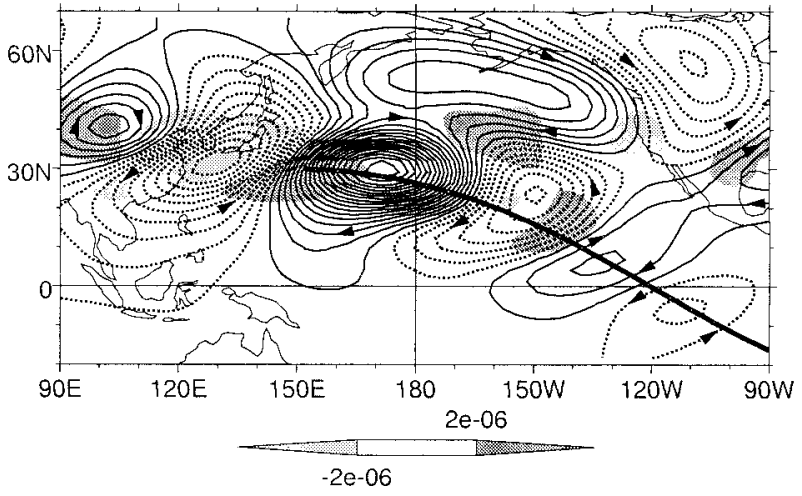

(e) Day -4

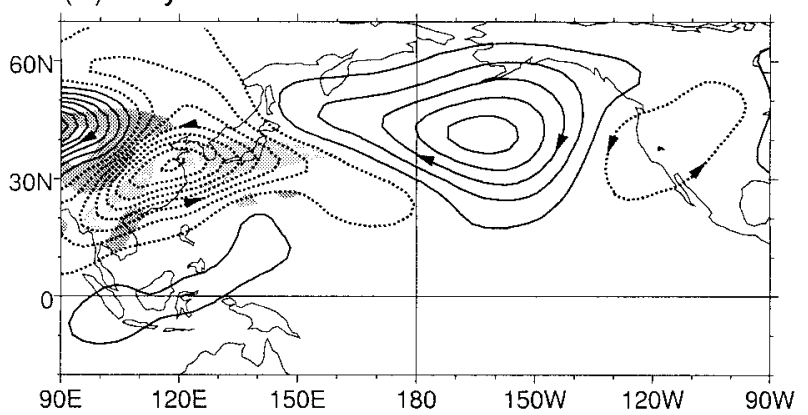

(f) Day -2

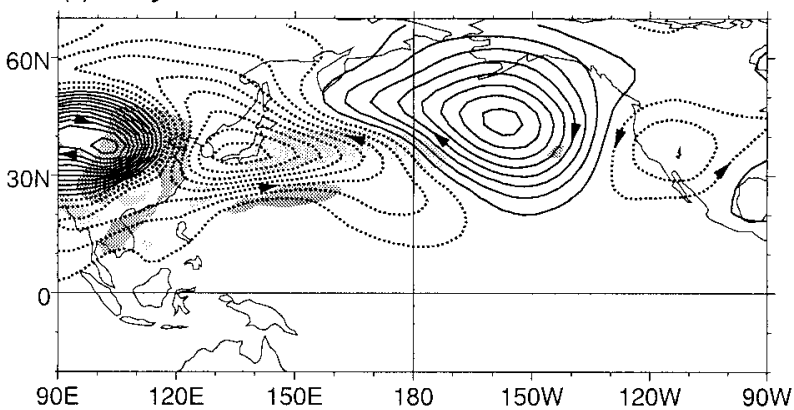

(g) Day 0

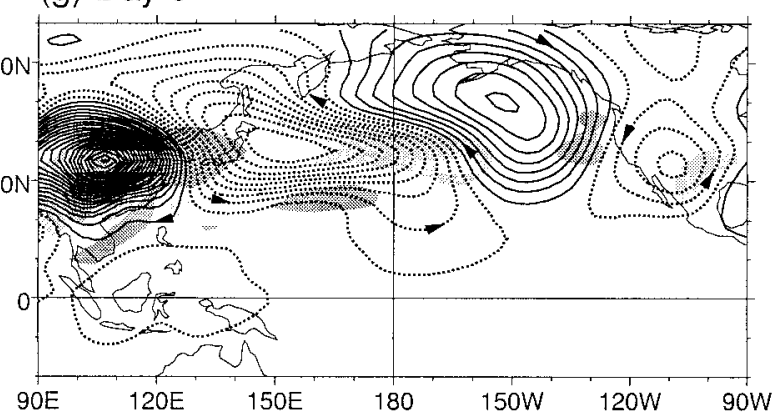

(h) Day +2

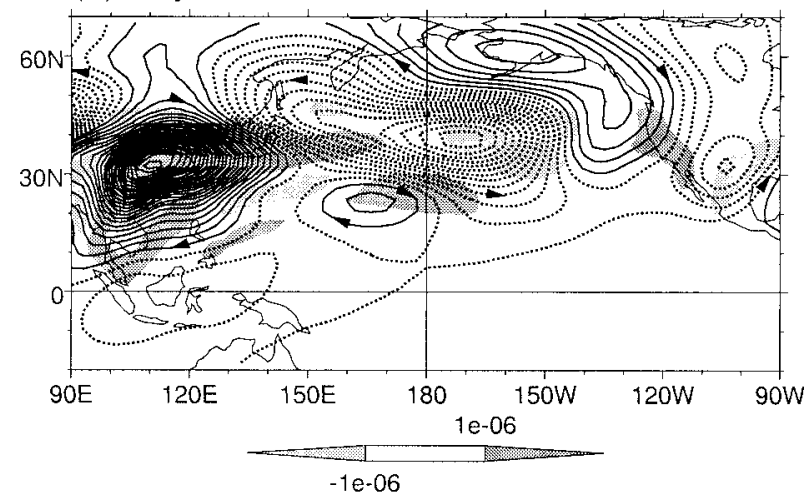

FIG. 3. Streamfunction and divergence anomalies from the initial value integration. The 200-hPa fields on (a) day -4 , (b) day -2 , (c) day 0 , (d) day +2 ; conventions are as in Fig. 1. The 850-hPa fields on (e) day -4 , (f) day -2 , (g) day 0 , (h) day +2 ; streamfunction contour interval is $1 \times 10^{6} \mathrm{~m}^{2} \mathrm{~s}^{-1}$ (first positive contour is at $0.5 \times 10^{6} \mathrm{~m}^{2} \mathrm{~s}^{-1}$ ). Divergence shading is shown by the legends. 
(a) PV

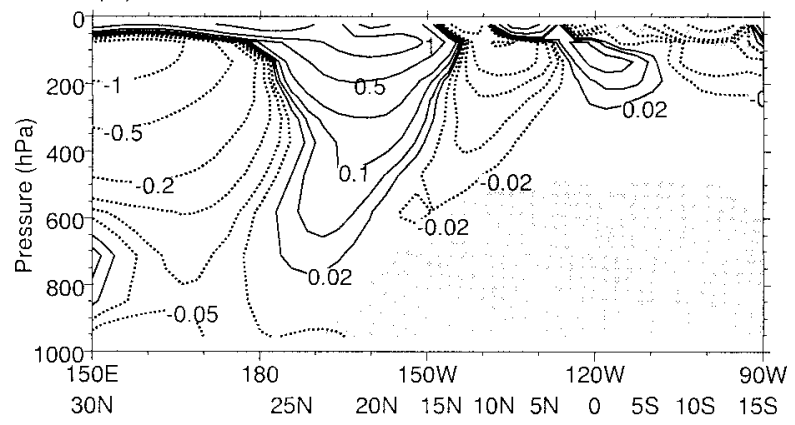

(b) Omega

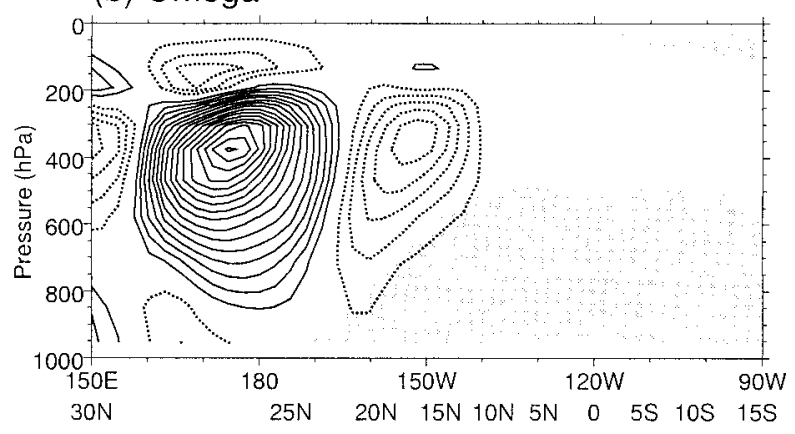

(c) Temperature

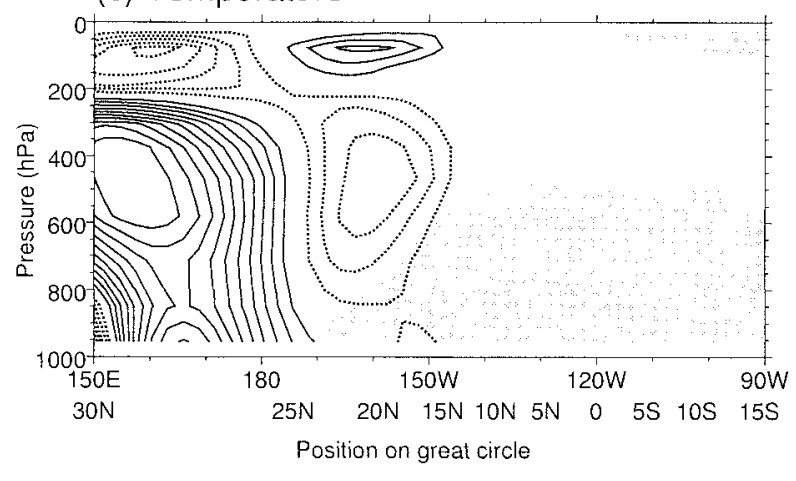

FIG. 4. Vertical section along the great circle on day 0 of the integration of anomalous (a) PV; contours are at $\pm 0.02,0.05,0.1$, $0.2,0.5,1$, and $2 \mathrm{PVU}\left(1 \mathrm{PVU} \equiv 1 \times 10^{-6} \mathrm{~K} \mathrm{~m}^{2} \mathrm{~kg}^{-1} \mathrm{~s}^{-1}\right)$; (b) vertical velocity $\omega$; contour interval is $5 \times 10^{-3} \mathrm{~Pa} \mathrm{~s}^{-1}$; (b) temperature; contour interval is $0.5 \mathrm{~K}$. Negative contours are dotted. Climatological mean easterly winds are shaded.

torward and upward group propagation into the stratosphere, consistent with observations (K98).

The secondary circulation associated with the equatorward-propagating wave train is shown by a vertical section of vertical pressure velocity $(\omega)$ along the great circle on day 0 (Fig. 4b). Regions of tropospheric ascent (negative $\omega$ ) are located ahead of positive PV anomalies, with regions of descent ahead of negative PV anomalies. In particular there is a region of deep tropospheric ascent near $15^{\circ} \mathrm{N}, 150^{\circ} \mathrm{W}$ associated with $200-\mathrm{hPa}$ divergence in Fig. 3c. This deep ascent gives rise to adiabatic cooling and a negative temperature perturbation (Fig. 4c) located ahead of the positive PV anomaly at $20^{\circ} \mathrm{N}$, $160^{\circ} \mathrm{W}$, consistent with observations (K98). Upward motion is consistent with the region where vorticity advection is increasing with height. The temperature perturbation becomes more negative with height due to advection and upward motion and therefore destabilizes the atmospheric column, increasing the likelihood of deep convection in this region.

\section{Barotropic Rossby wave theory \\ a. Behavior over the eastern Pacific}

The spatial scale, time period, phase, and group speeds of the model wave train are estimated from a Hovmöller diagram of 200-hPa streamfunction anomalies along the propagation path (Fig. 5). The two parallel thick lines are phase lines half a cycle apart. From these two lines the longitudinal wavelength near the equators estimated as $41^{\circ}$, corresponding to zonal wavenumber 9 or an $x$ wavenumber of $k \approx 1.4 \times 10^{-6} \mathrm{~m}^{-1}$, which is smaller than the perturbation in the jet. The $y$ wavenumber is approximately $l=k \tan \alpha \approx-0.8 \times$ $10^{-6} \mathrm{~m}^{-1}$ or meridional wavenumber 5 , where $\alpha=-30^{\circ}$ is the angle between the propagation path (great circle) and the equator. The period of the model waves is also estimated from the two phase lines as $T \approx 13.3$ days, corresponding to a frequency of $\omega \approx 5.5 \times 10^{-6} \mathrm{~s}^{-1}$. Therefore, the zonal phase speed or gradient of the phase lines is $c \equiv \omega / k \approx 3.9 \mathrm{~m} \mathrm{~s}^{-1}$.

If the model waves behave like nondivergent barotropic Rossby waves, they should obey the dispersion relation

$$
c=\bar{u}-\frac{\beta}{k^{2}+l^{2}} .
$$

Taking $\beta \approx 2.3 \times 10^{-11} \mathrm{~m}^{-1} \mathrm{~s}^{-1}$ and $\bar{u} \approx 15 \mathrm{~m} \mathrm{~s}^{-1}$ over the equatorial eastern Pacific (Fig. 2 from Matthews and Kiladis 1999a) gives a theoretical phase speed of $c \approx$ $6 \mathrm{~m} \mathrm{~s}^{-1}$, which is close to the phase speed of the model waves. The theoretical zonal group speed is

$$
u_{g} \equiv \frac{\partial \omega}{\partial k}=c+\frac{2 \beta k^{2}}{\left(k^{2}+l^{2}\right)^{2}} .
$$

A nondivergent barotropic Rossby wave with the same $k, l$, and $c$ as the model wave would have $u_{g} \approx 17 \mathrm{~m}$ $\mathrm{s}^{-1}$. The thick dotted line in Fig. 5 represents the group speed; it has a value of $u_{g}=17 \mathrm{~m} \mathrm{~s}^{-1}$ and passes through successively developing perturbations at the eastern edge of the wave packet. Therefore, to a first approximation the model wave packet over the eastern Pacific appears to be governed by nondivergent barotropic Rossby wave dynamics.

K98 obtained similar values for the observed waves. The time period of the observed waves is $T \approx 12$ days and the observed longitudinal wavelength is $50^{\circ}$ or zonal wavenumber 7 , which is associated with slightly higher 


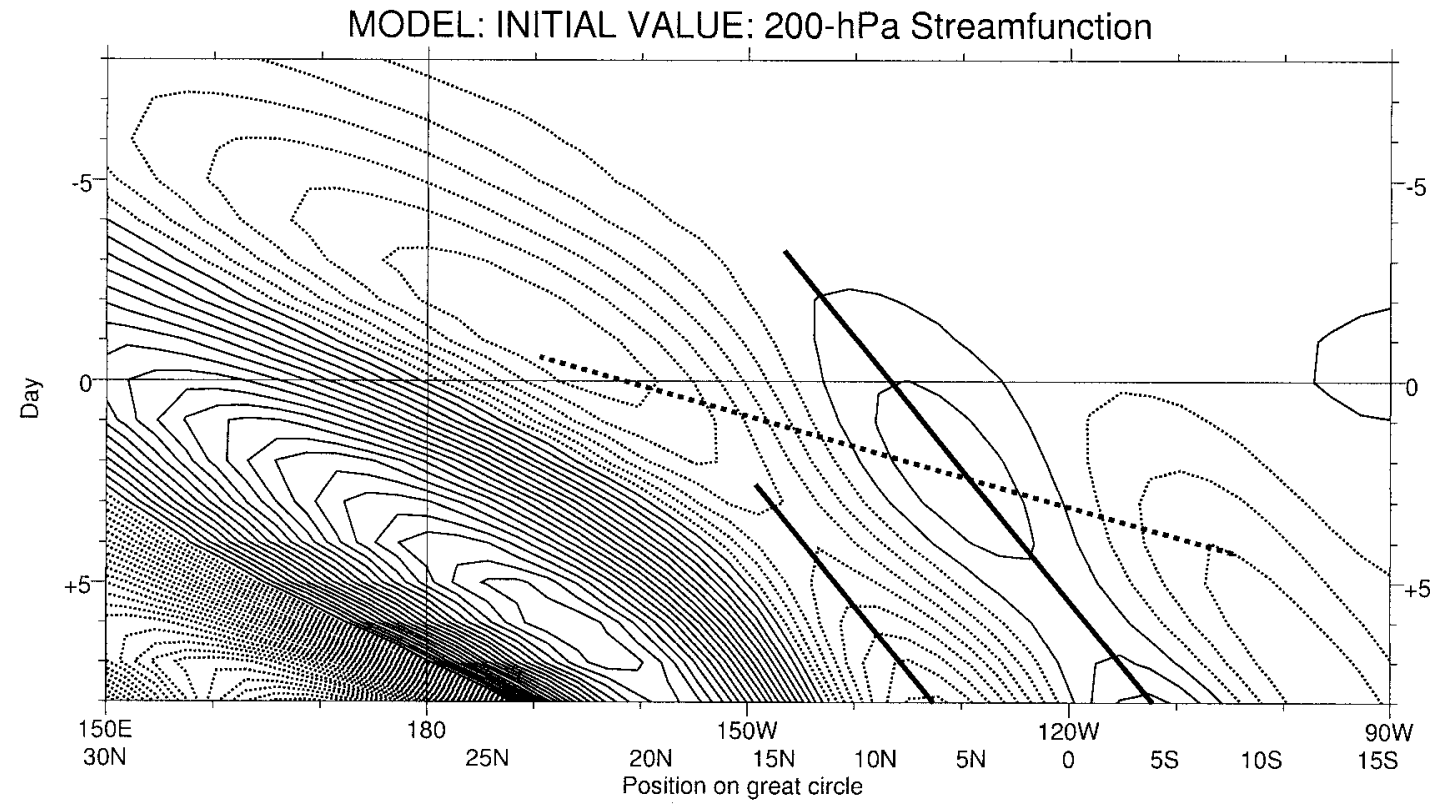

FIG. 5. Hovmöller diagram of 200-hPa streamfunction anomalies along the great circle. Contour interval is $2.5 \times 10^{6} \mathrm{~m}^{2} \mathrm{~s}^{-1}$; first positive contour is at $1.25 \times 10^{6} \mathrm{~m}^{2} \mathrm{~s}^{-1}$; negative contours are dotted.

phase and group speeds of $c \approx 5 \mathrm{~m} \mathrm{~s}^{-1}$ and $u_{g} \approx 24 \mathrm{~m}$ $\mathrm{s}^{-1}$.

\section{b. Ray tracing}

The evolution of a theoretical nondivergent barotropic Rossby wave at the 200-hPa level from an initial position in the Asian jet is now examined by a raytracing technique. Following Karoly (1983), a Mercator projection of the sphere is used. A Rossby wave with initial $x$ and $y$ wavenumbers $k_{0}$ and $l_{0}$ at initial position $\left(X_{0}, Y_{0}\right)$ moves at the local group velocity $\left(u_{g}, v_{g}\right)$, which depends on the basic-state zonal and meridional wind fields $\left(\bar{u}_{M}, \bar{v}_{M}\right)$. The equations for the rate of

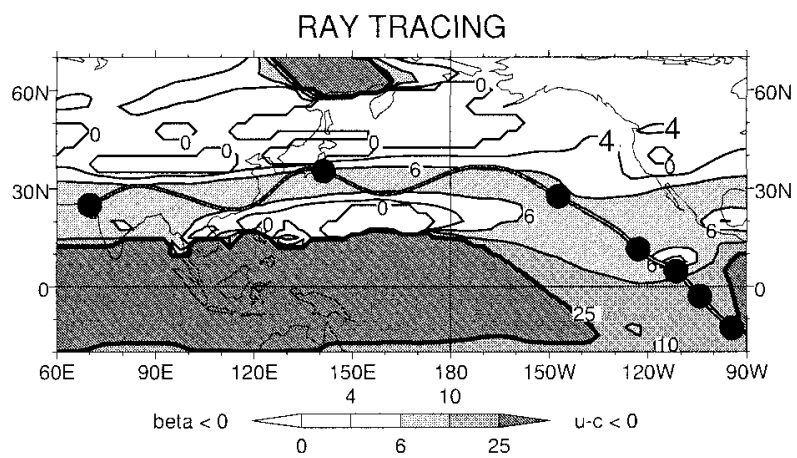

FIG. 6. The 200-hPa total wavenumber field $K_{\omega}$ for a Rossby wave of phase speed $c=6.5 \mathrm{~m} \mathrm{~s}^{-1}$. Contours are at zonal wavenumbers $0,4,6$, and 10 , with a thick contour at 25 to show the critical line between regions of real and imaginary $K_{\omega}$. The ray path of a Rossby wave initialized in the Asian jet is shown by the thick line, with circles at daily intervals. change of the ray position $(X, Y)$ and its $x$ and $y$ wavenumbers $k$ and $l$ are integrated forward in time using a fourth-order Runge-Kutta scheme.

Figure 6 shows the ray path for an initial Rossby wave at $\left(X_{0}, Y_{0}\right)=\left(25^{\circ} \mathrm{N}, 70^{\circ} \mathrm{E}\right)$ and with an initial $x$ wavenumber of $k_{0}=9.3 \times 10^{-7} \mathrm{~m}^{-1}$ (approximately zonal wavenumber 6) and a period of $T=12$ days, corresponding to an initial $y$ wavenumber of $l_{0}=5.4 \times 10^{-7}$ $\mathrm{m}^{-1}$ (approximately meridional wavenumber 10 ) and a phase speed of $c=6.5 \mathrm{~m} \mathrm{~s}^{-1}$. The ray was terminated after 6 days. The total wavenumber field

$$
K_{\omega}=\left(\frac{\beta_{M}}{\bar{u}_{M}-c}\right)^{1 / 2}
$$

for a Rossby wave of phase speed $c=6.5 \mathrm{~m} \mathrm{~s}^{-1}$ is also plotted, where the subscript $M$ denotes a Mercator projection (Yang and Hoskins 1996). Rossby waves are refracted toward high values of $K_{\omega}$, which represents a refractive index. ${ }^{2}$ As the Asian-Pacific jet has a local maximum in $K_{\omega}$ it behaves like a waveguide (Hoskins and Ambrizzi 1993).

The ray in Fig. 6 propagates along the jet waveguide, oscillating north and south between its turning latitudes where the total wavenumber field $K_{\omega}$ is equal to the zonal wavenumber 6 of the ray. At day 2 the ray reaches

\footnotetext{
${ }^{2}$ As the phase speed $c=6.5 \mathrm{~m} \mathrm{~s}^{-1}$ is small compared to typical values of the mean zonal wind $\bar{u}_{M}$, the total wavenumber field $K_{\omega}$ shown here is very similar to the stationary wavenumber field $K_{s}=$ $\left(\beta / \bar{u}_{M}\right)^{1 / 2}$ used in many other studies, for example, Hoskins and Ambrizzi (1993).
} 
the jet exit and is refracted southward, away from the low values of $K_{\omega}$ to the north and toward the high values of $K_{\omega}$ associated with the equatorial westerly duct over the eastern Pacific. On day 5 the ray crosses the equator into the Southern Hemisphere.

The critical line, where the phase speed of a Rossby wave of the total wavenumber used here equals the background zonal wind, is at $\bar{u}=c=6.5 \mathrm{~m} \mathrm{~s}^{-1}$. Therefore the width of the equatorial duct through which the Rossby wave can propagate is reduced from that for stationary waves with a critical line at $\bar{u}=c=0$, although it is still wide enough $\left(50^{\circ}\right.$ longitude at the equator) to allow Rossby waves to propagate through.

The ray path in Fig. 6 shows a consistency between the behavior of the observed waves associated with ITCZ convection (Figs. 1a-d) and of the wave packet in the baroclinic model (Figs. 3a-d) and an interpretation in terms of nonstationary Rossby waves propagating in a basic-state $\left(\bar{u}_{M}, \bar{v}_{M}\right)$ wind field. However, the WKBJ approximation (that the spatial scale over which the basic state changes is much larger than the scale of the waves themselves) is violated, especially in the jet region (Hoskins and Ambrizzi 1993), so these results should only be interpreted qualitatively. Also, the ray path is rather sensitive to the initial position and orientation of the ray. For example, if the ray in Fig. 6 is initially oriented in a southeastward rather than a northeastward direction, it does not reach a turning latitude at $K_{\omega}=6$ but propagates equatorward out of the jet and stagnates at the critical line over the Bay of Bengal within a day. However, the calculated ray traces the path of a plane wave, whereas a localized disturbance would have components propagating both northeastward and southeastward. Hence, a portion of the wave packet would leak out of the waveguide and another portion would propagate along the waveguide.

\section{Scale selection}

The observations show that transient convection over the eastern Pacific ITCZ during northern winter is associated with equatorward-propagating waves of zonal wavenumber 6-7. The baroclinic model integration described in section 3 shows that the evolution of an initial localized zonal wavenumber 6 perturbation in the African-Asian jet closely follows the observations. In this section the problem of the spatial scale selection of the waves is addressed.

Figure $7 \mathrm{a}$ shows the day $0200-\mathrm{hPa}$ anomalies from an identical integration to that in Fig. 3c except that the local wavelength of the initial perturbation in the African-Asian jet is zonal wavenumber 4 . As before, the start of the integration is defined as day -18 . By day 0 a balanced wave train has reached the Asian-Pacific jet. However, its typical spatial scale is now smaller than zonal wavenumber 4 and the wave train in the jet looks rather similar to that from the initial zonal wavenumber 6 integration in Fig. 3c, although it still has a slightly

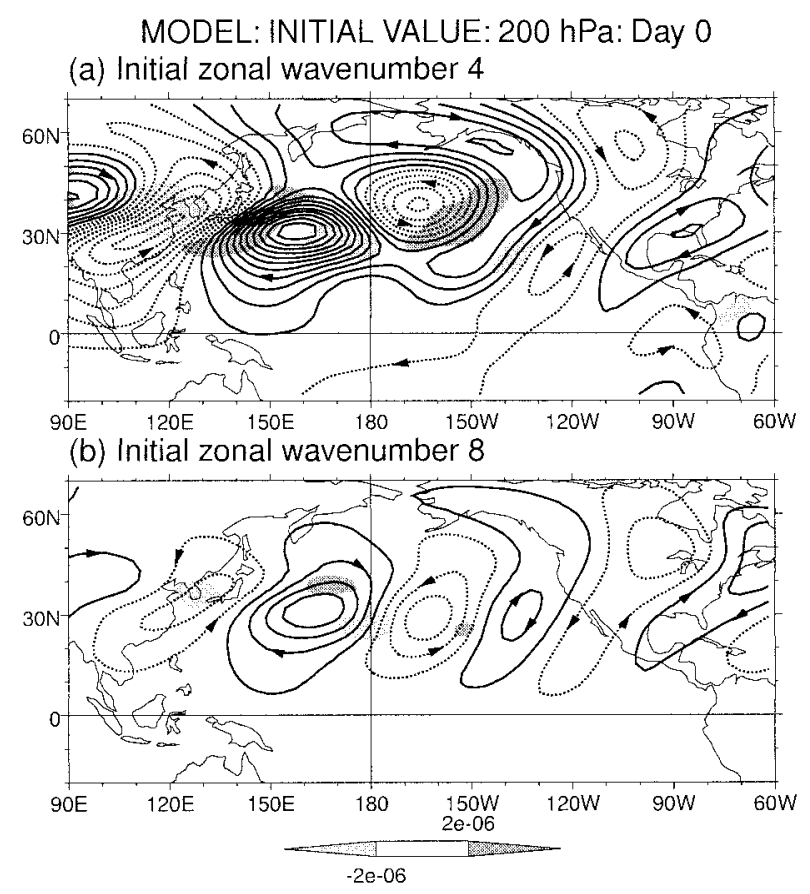

FIG. 7. As in Fig. 3c, except for initial perturbations with zonal wavenumber (a) 4, (b) 8 .

larger scale. The equatorward propagation in the zonal wavenumber 4 integration is weaker and farther eastward.

The relatively stronger growth of the higher wavenumbers in the Asian-Pacific jet wave train could be due to baroclinic instability. A vertical cross section of meridional wind anomalies along $30^{\circ} \mathrm{N}$ (not shown) shows a westward tilt with height throughout the troposphere to the west of the date line, indicative of baroclinic growth. In all the integrations described in this section (with a range of zonal wavenumber initial conditions) a baroclinic structure eventually dominates in the Asian jet with zonal wavenumber 6. Hence, baroclinic growth appears to favor a zonal wavenumber 6 scale for perturbations propagating out of the AsianPacific jet.

To the east of the date line there is less vertical tilt, and barotropic processes are more dominant. The weaker and farther eastward equatorward propagation of the slightly larger-scale wave train over the central Pacific is consistent with barotropic Rossby wave dynamics, as discussed in section 4 . The zonal wavenumber 6 contour of the refractive index $\left(K_{\omega}\right)$ field shows a pronounced kink to the south over the central Pacific at $30^{\circ} \mathrm{N}, 145^{\circ} \mathrm{W}$ (Fig. 6). This will tend to refract waves of zonal wavenumber 6 toward the equator in this region. The zonal wavenumber 4 contour by contrast continues eastward and has a kink to the north just off the west coast of North America. Therefore, the larger-scale waves in Fig. 7a will continue propagating eastward and not be refracted toward the equator over the eastern Pacific. 
A further integration with a localized zonal wavenumber 8 anomaly (Fig. 7b) shows no cross-equatorial propagation; the smaller-scale wave packet is confined to the subtropical jet waveguide over the entire AsianPacific-North American sector. In terms of Rossby wave dynamics, as the scale of the perturbation is decreased, its group velocity would approach that of the mean wind and the perturbation would be advected quickly downstream before it is able to propagate significantly equatorward toward the westerly duct.

Integrations with other zonal wavenumbers behave qualitatively like one of the three integrations described above; zonal wavenumbers 3 and 5 are like 4; 7 is like 6; 9 and above are like 8. Hence, it appears that an initial anomaly of around zonal wavenumber 6-7 is necessary for efficient cross-equatorial propagation through the westerly duct in the basic state used in these integrations.

\section{Diabatic heating}

In section $3 \mathrm{~d}$ the equatorward-propagating waves were shown to destabilize the model atmosphere in the region of ascent ahead of the upper-tropospheric cyclonic anomalies. This implies that deep convection and latent heating can be triggered in this region. The subsequent feedback on the circulation by this diabatic heating is examined in this section.

Some observational results concerning the diabatic effects of ITCZ convection are presented first. Figures $8 \mathrm{a}-\mathrm{c}$ shows a sequence of lagged-regression maps of 6-30-day filtered OLR and 400-hPa diabatic heating $H$ for an OLR anomaly of $-40 \mathrm{~W} \mathrm{~m}^{-2}$ over the ITCZ base region. The diabatic heating is calculated from NCEPNCAR reanalyses as the residual in the thermodynamic equation; for details see Matthews and Kiladis (1999b). Positive heating anomalies correspond to regions of upper-tropospheric divergence, lower-tropospheric convergence, and implied midtropospheric ascent in the southeastward-propagating wave (Fig. 1), consistent with the interpretation of the convection as a forced response to the wave. The heating and OLR anomalies are highly anticorrelated; as the OLR data are independent from the reanalysis this gives confidence in the heating field. The vertical structure is one of deep diabatic heating with a midtropospheric maximum at 400 hPa (Fig. 8d). However, there is a secondary maximum at $850 \mathrm{hPa}$ with a local minimum at $700 \mathrm{hPa}$.

A further model integration is performed to examine the role of the diabatic heating. The climatological basic state is maintained by a constant forcing term as before. However, instead of an initial value perturbation, an anomalous diabatic heating $H$ is then superimposed. The time-dependent three-dimensional structure of $H$ corresponds to the observed lagged-regression fields of $H$ in Fig. 8, from days -8 to +2 over the region of ITCZ heating $\left(0^{\circ}-30^{\circ} \mathrm{N}, 180^{\circ}-120^{\circ} \mathrm{W}\right)$. The start of the model
OBSERVATIONS: OLR, 400-hPa H

(a) Day -4

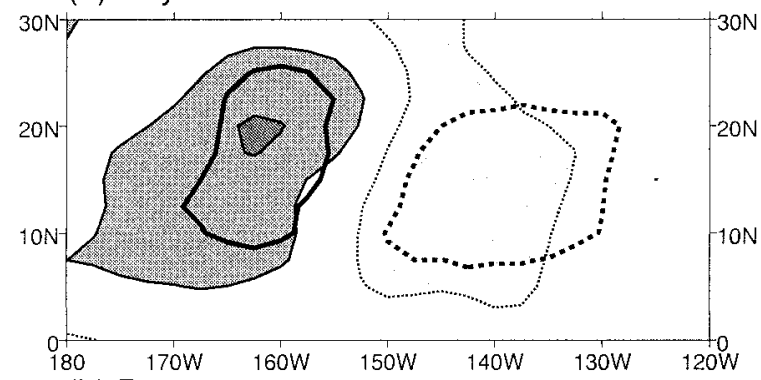

(b) Day 0

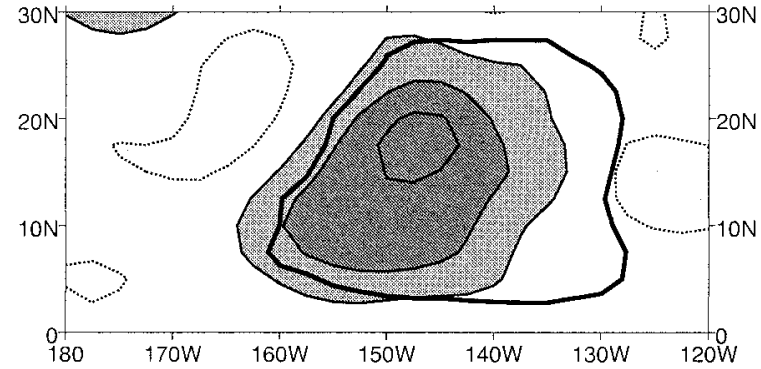

(c) Day +2

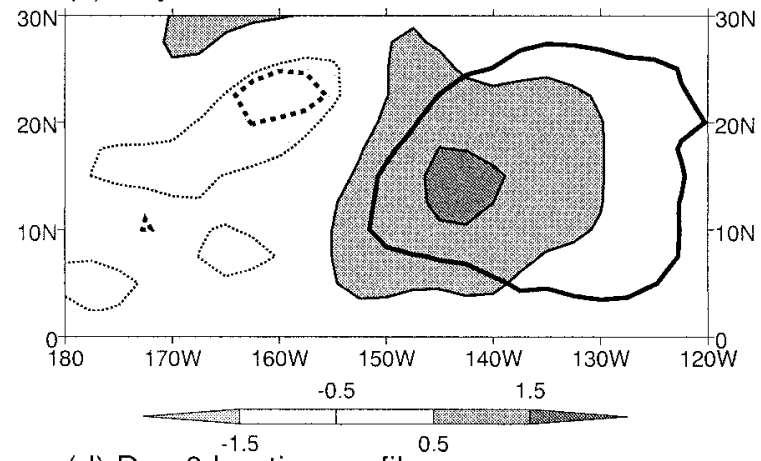

(d) Day 0 heating profile

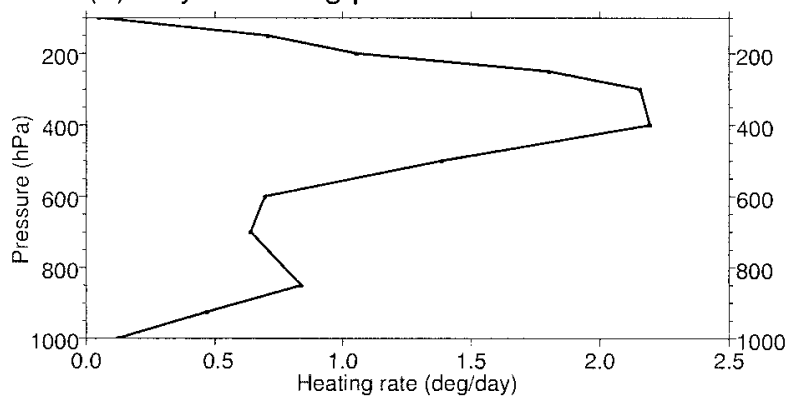

FIG. 8. As in Fig. 1 but for OLR and 400-hPa diabatic heating at (a) day -4 , (b) day 0 , (c) day +2 . OLR has a thick solid (dotted) contour at $-10(+10) \mathrm{W} \mathrm{m}^{-2}$. Contour interval for heating is $1 \mathrm{~K}$ day $^{-1}$; first positive contour is at $0.5 \mathrm{~K} \mathrm{day}^{-1}$ (see legend for shading). (d) Vertical profile of heating on day 0 averaged over $10^{\circ}-20^{\circ} \mathrm{N}, 150^{\circ}-$ $140^{\circ} \mathrm{W}$.

integration is arbitrarily denoted as day -8 to correspond with the observed regression maps.

Figure 9 shows a sequence of streamfunction and divergence anomaly maps from the transient heating 
(a) Day -4

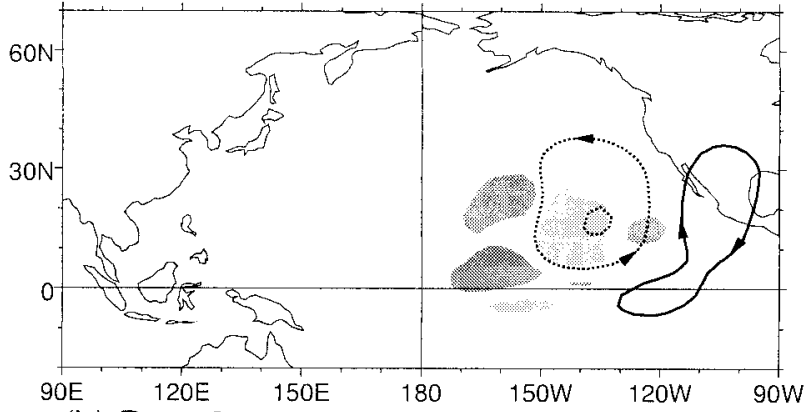

(b) Day -2

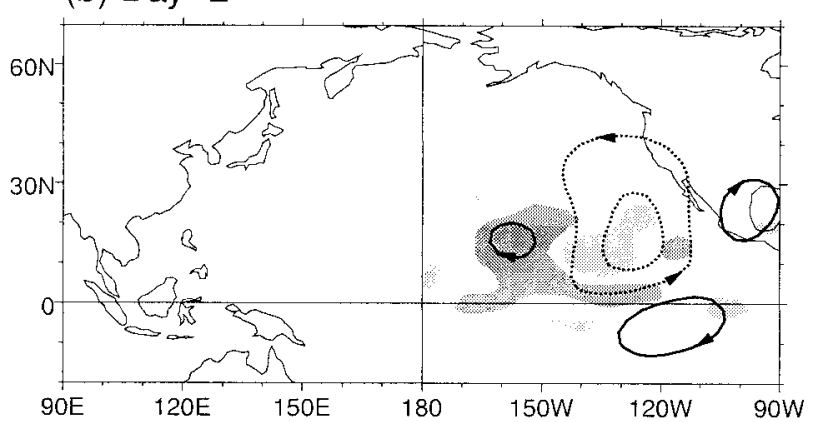

(c) Day 0

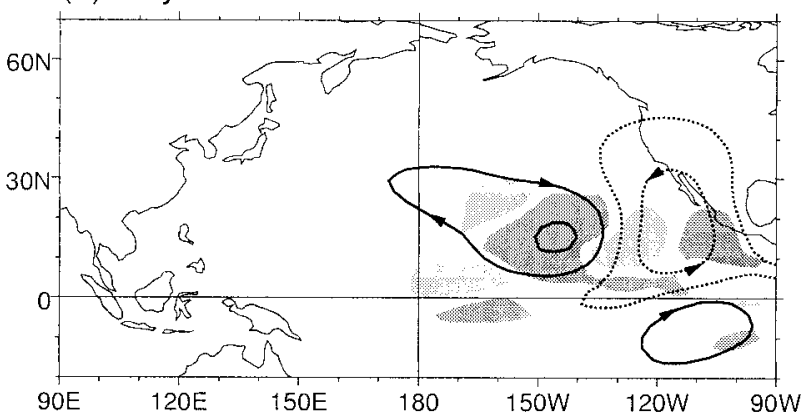

(d) Day +2

\section{$200 \mathrm{hPa}$}

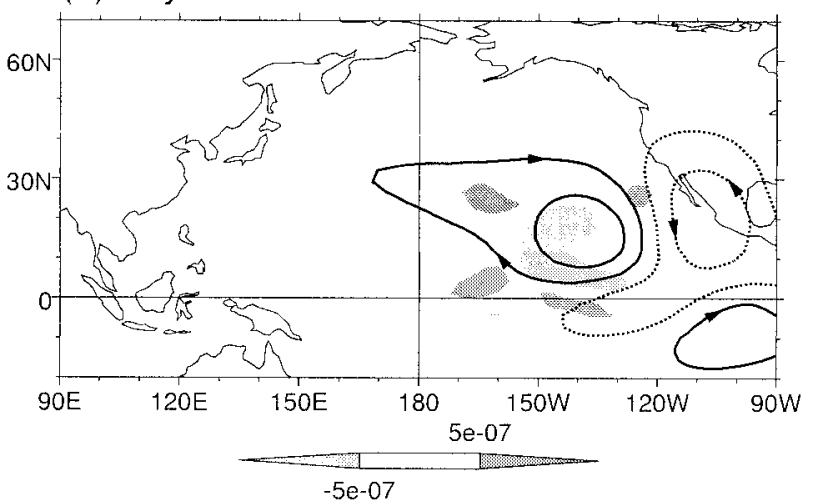

(e) Day -4

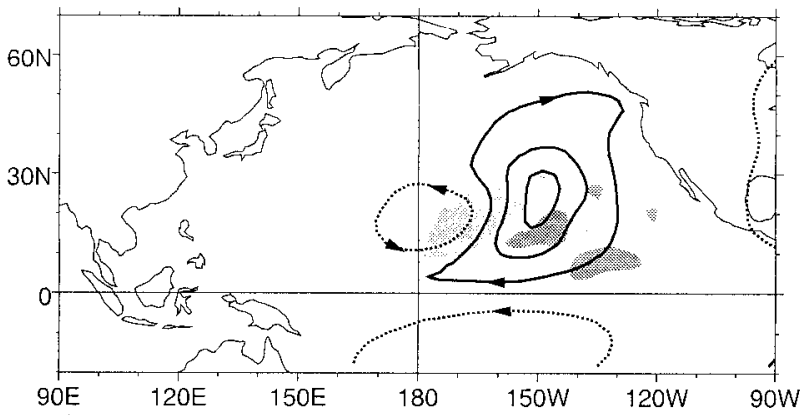

(f) Day -2

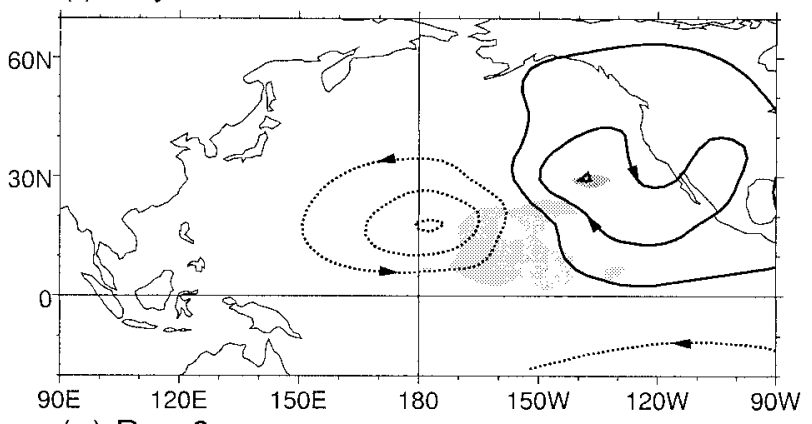

(g) Day 0

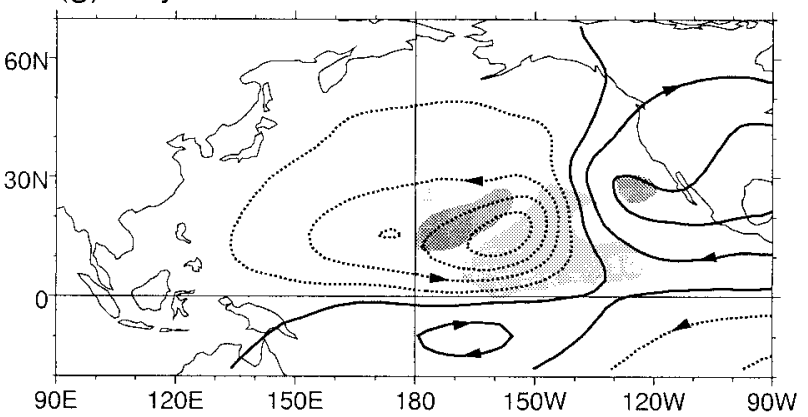

(h) Day +2

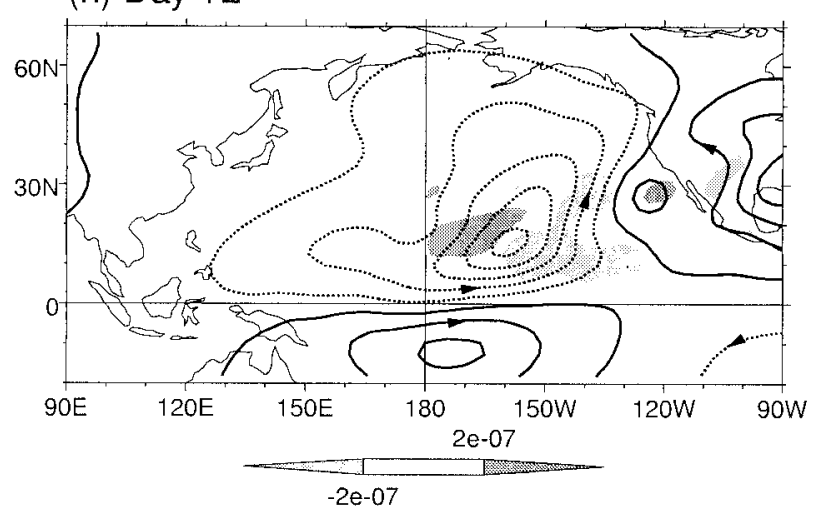

FIG. 9. As in Fig. 3 but for the transient heating integration. The 200-hPa streamfunction contour conventions are as in Fig. 3 . The $850-$ $\mathrm{hPa}$ streamfunction contour interval is $0.25 \times 10^{6} \mathrm{~m}^{2} \mathrm{~s}^{-1}$ (first positive contour is at $0.125 \times 10^{6} \mathrm{~m}^{2} \mathrm{~s}^{-1}$ ). Divergence shading is shown by the legends. 


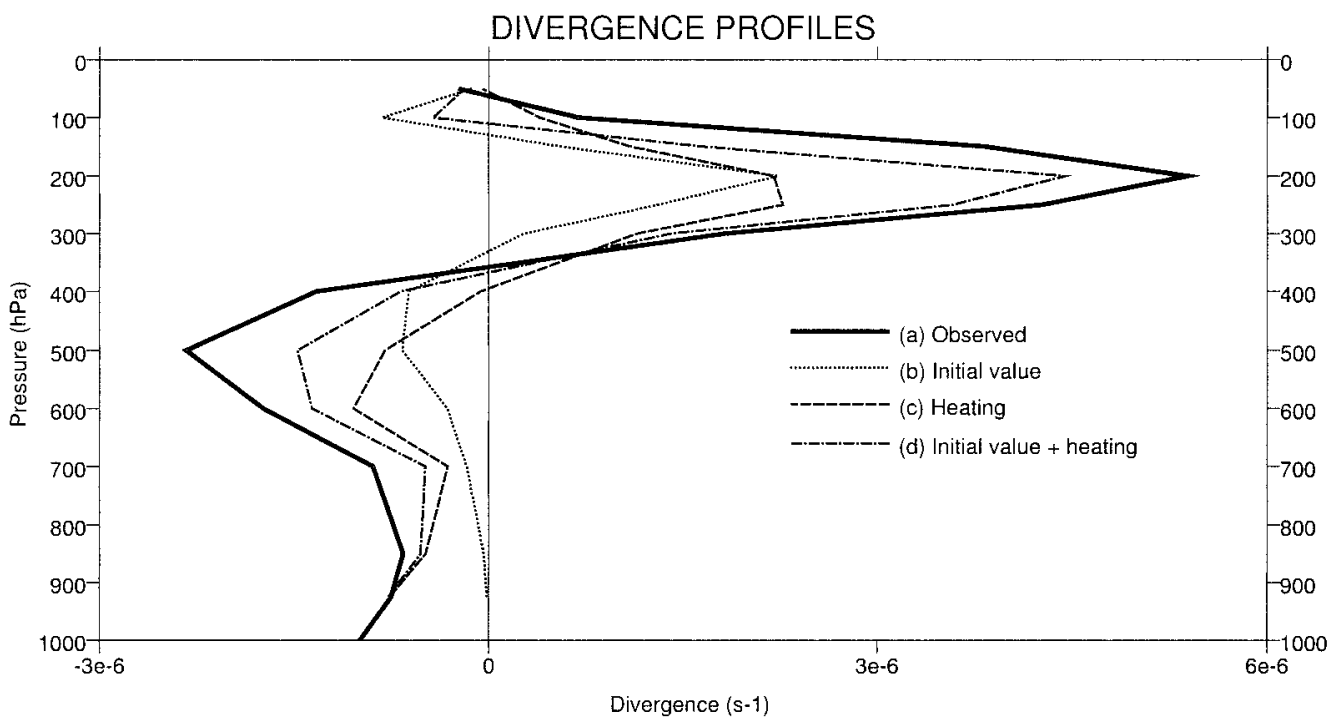

FIG. 10. Divergence profiles on day 0 averaged over $10^{\circ}-20^{\circ} \mathrm{N}, 150^{\circ}-140^{\circ} \mathrm{W}$ from the (a) observations, (b) initial value integration, (c) heating integration, and (d) initial value + heating integrations $[(b)+(c)]$.

integration. These can be compared with those from observations in Fig. 1 and the initial value integration in Fig. 3. The response to the imposed diabatic heating is one of deep ascent and adiabatic cooling, such that 200-hPa divergence and 850-hPa convergence anomalies in Fig. 9 tend to be collocated with positive diabatic heating anomalies in Fig. 8, and vice versa. At low levels, the rotational response to this mass circulation then takes the form of a forced equatorial Rossby and Kelvin wave response.

In the lower troposphere, cyclonic (anticyclonic) anomalies are forced to the west of positive (negative) heating anomalies, such that poleward flow occurs in regions of lower-tropospheric convergence and equatorward flow is located in regions of lower-tropospheric divergence. Although the heating is confined to the Northern Hemisphere there is a lower-tropospheric equatorial Rossby wave response in the Southern Hemisphere such that the circulation displays some equatorial symmetry on days 0 and +2 (Figs. $9 \mathrm{~g}, \mathrm{~h}$ ). As the heating anomalies move eastward the forced equatorial Rossby wave response moves eastward too; for example, the center of the 850-hPa cyclonic anomaly at the date line on day -4 (Fig. 9e) moves eastward to $160^{\circ} \mathrm{W}$ on day +2 (Fig. 9h). However, although the centers of the circulation anomalies move eastward the return flow in the western portion of the cyclonic anomalies expands westward to $130^{\circ} \mathrm{E}$ on day +2 as a propagating equatorial Rossby wave. There also appears to be a Kelvin wave response to the heating with equatorial $850-\mathrm{hPa}$ easterly flow to the east of the heating on day 0 (Fig. $9 \mathrm{~g}$ ).

The patterns of lower-tropospheric tropical streamfunction and divergence anomalies in the transient heating experiment are very similar to the observed anomalies in Fig. 1. Hence, latent heating appears to be of prime importance in determining the structure of the flow in this region.

In the upper troposphere the streamfunction anomalies tend to be out of phase with those in the lower troposphere in Fig. 9. However, upper-tropospheric streamfunction anomalies tend to be collocated with the heating and divergence anomalies, rather than to the west of them, as is seen in observations of $200-\mathrm{hPa}$ streamfunction associated with convection over this region during northern summer (Kiladis and Weickmann 1997, their Fig. 12a). There also appears to be the beginning of a weak wave train that propagates southeastward across the equator into the Southern Hemisphere. This wave train is approximately out of phase with the dry wave train in Fig. 3 and would tend to weaken it.

\section{Comparison with observations}

The initial value integration in section 3 and the heating integration in section 6 both simulated certain features of the observed circulation. This is now examined further, and the combination of the anomalies from the two integrations is compared with observations.

The observed day 0 anomalous divergence profile averaged over the region $10^{\circ}-20^{\circ} \mathrm{N}, 150^{\circ}-140^{\circ} \mathrm{W}$ shows strong 200-hPa divergence above a layer of convergence with two peaks, one at $500 \mathrm{hPa}$ and the other at the surface (Fig. 10a). The profile from the initial value integration (Fig. 10b) also has divergence at $200 \mathrm{hPa}$ but with only about half the observed amplitude; ${ }^{3}$ there

\footnotetext{
${ }^{3}$ Recall that the anomalies from the initial value integration were scaled so that the amplitudes of the observed and modeled day 0 $200-\mathrm{hPa}$ cyclonic anomalies near $20^{\circ} \mathrm{N}, 160^{\circ} \mathrm{W}$ were similar.
} 
(a) $200 \mathrm{hPa}$

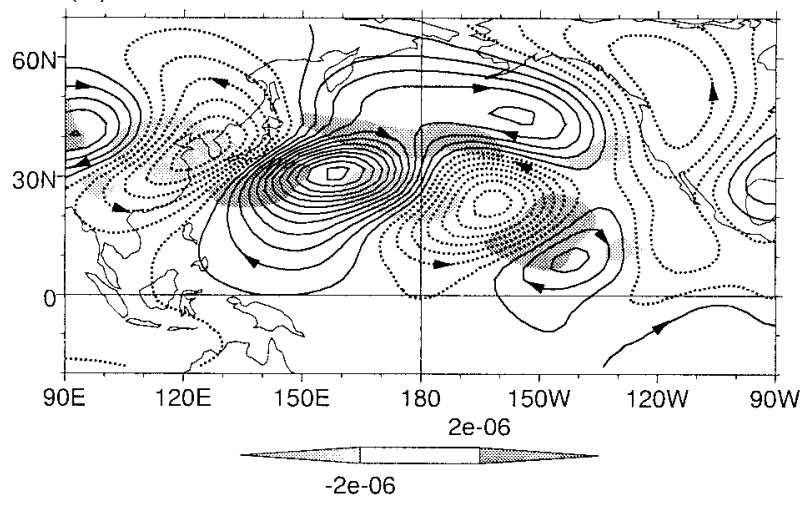

MODEL: INITIAL VALUE + HEATING

(b) $850 \mathrm{hPa}$

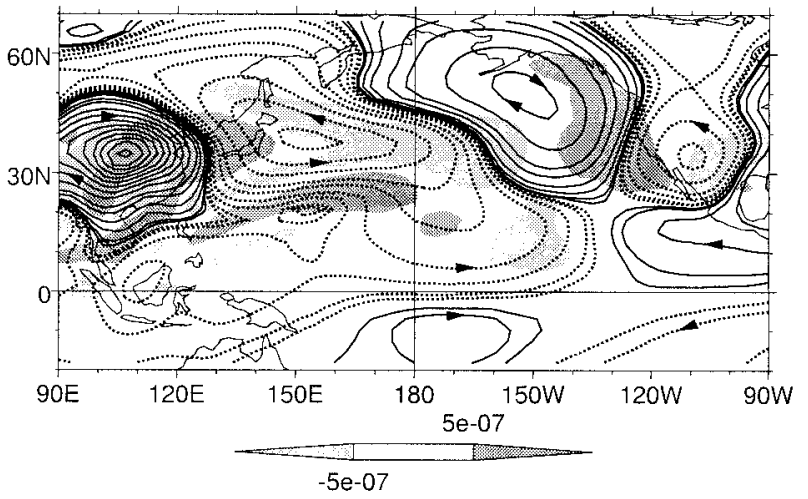

FIG. 11. Sum of day 0 streamfunction and divergence anomalies from the initial value and heating integrations at (a) $200 \mathrm{hPa}$; conventions are as in Fig. 1. (b) $850 \mathrm{hPa}$; streamfunction contours are at $\pm 0.1,0.2,0.5,1,2,3 \times 10^{6} \mathrm{~m}^{2} \mathrm{~s}^{-1}$, then in increments of $2 \times 10^{6} \mathrm{~m}^{2} \mathrm{~s}^{-1}$. Divergence shading is shown by the legends.

is weak midtropospheric convergence but no significant near-surface convergence. This is consistent with the cross section of vertical velocity $\omega$ (Fig. 4b), which shows that the strongest ascent is confined to the middle and upper troposphere. The profile from the heating integration (Fig. 10c) also has 200-hPa divergence at about half the observed amplitude, but it also has strong midtropospheric and surface convergence, consistent with the vertical heating profile in Fig. 8d. The secondary peak in the diabatic heating (Fig. 8d) and the associated divergence profile (Fig. 10c) are consistent with observations of tropical convective systems (Mapes and Houze 1995) and result from the cumulative effects of young mesoscale convective systems with strong near-surface convergence and mature convective systems with their attendant downdrafts and stratiform precipitation areas and peak convergence aloft. The heating profile in Fig. 8d, which has its main peak in the upper troposphere, forces a perturbation flow response that is out of phase between the upper and lower troposphere (Gill 1980). However, the higher vertical wavenumber components of the heating profile do have an important effect on the low-level circulation near to the heating region (Mapes and Houze 1995).

The sum of the initial value and heating integration divergence profiles (Fig. 10d) has a very similar shape to the observed profile, although the amplitude is somewhat reduced. This suggests a scenario where the dry wave train initially destabilizes the middle troposphere and induces convection there. Once the convection is established it reinforces the preexisting midtropospheric and surface convergence.

The sum of the day 0 streamfunction and divergence anomalies from the initial value and heating integrations (Fig. 11) resembles the observations (Figs. 1c,g) more closely than either the initial value integration anomalies (Figs. 3c,g) or the heating integration anomalies (Figs. $9 \mathrm{c}, \mathrm{g})$ individually, although the caveats described pre- viously still apply. In particular, the upstream anomalies over Asia are much stronger in the model (from the initial value integration) than in the observations. This may be due to the different analysis techniques used. The observed circulation was regressed onto convection (OLR) over a base region in the ITCZ and would include contributions from many wave trains of slightly differing spatial and temporal scales. Averaging over this ensemble of wave trains would tend to decrease the signal both in regions away from the base region, including the upstream region of Asia, and also at increasing or decreasing lags, which could explain why the observed wave train could not be conclusively traced back into the Asian jet at day -4 (Fig. 1a) and before. On the other hand, the initial value integration can be regarded as one member of this ensemble and has a clear upstream signal over Asia. The $850-\mathrm{hPa}$ superimposed model anomalies qualitatively resemble the observations (Fig. 1g), although as the $850-\mathrm{hPa}$ streamfunction anomalies from the heating integration were much weaker than those from the initial value integration, a variable contour interval was used in Fig. 11b.

\section{Discussion}

An idealized primitive equation model has simulated many features of the transient waves observed to be associated with transient deep convection over the eastern Pacific ITCZ region during northern winter.

To isolate the role of dry wave dynamics, the model is linearized about a three-dimensional climatological basic state and an initial perturbation in the form of a localized wave packet is superimposed onto the African-Asian jet. Apart from a fixed forcing term to keep the basic state constant, no other model physics is included. The wave packet propagates along the AfricanAsian-Pacific jet waveguide until it reaches the jet exit near the date line when it propagates southeastward and 
through the westerly duct in the eastern Pacific and into the Southern Hemisphere. The horizontal structure and propagation characteristics of the upper-tropospheric anomalies over the Pacific are very realistic, with a zonal wavenumber 6-7 scale and a time period of 13 days, confirming that the African-Asian jet is a source of the equatorward-propagating waves. Two-dimensional Rossby ray tracing on the climatological 200-hPa flow is consistent with this propagation path.

The cross-equatorial propagation through the westerly duct in this initial value integration can be compared to integrations where a localized forcing was used. For example, stationary Rossby wave dispersion from a constant vorticity forcing in the African jet in a barotropic model linearized about the $300-\mathrm{hPa}$ climatological mean zonal flow showed cross-equatorial propagation over the eastern Pacific (Hoskins and Ambrizzi 1993). However, when this analysis was extended and the constant forcing was applied to a baroclinic model the cross-equatorial propagation was reduced (Ambrizzi and Hoskins 1997). Yang and Hoskins (1996) extended this work further to allow time-dependent forcing in both the barotropic and baroclinic models. They found weak or nonexistent cross-equatorial propagation with a 14-day period forcing of eastward-moving waves. For the barotropic model, this was explained by an analysis of the 300-hPa basic-state flow. For a time period of 14 days and zonal wavenumber 4 , corresponding to a phase speed of $8.3 \mathrm{~m} \mathrm{~s}^{-1}$, the critical line extended right across the Pacific and the westerly duct was closed. However, this analysis is sensitive to the exact phase speed of the waves and the basic state; for a wave with a phase speed of $6.5 \mathrm{~m} \mathrm{~s}^{-1}$ on the $200-\mathrm{hPa}$ mean flow, the westerly duct is still substantial (Fig. 6). The lack of cross-equatorial propagation in the baroclinic model of Yang and Hoskins (1996) with forcing of eastward-moving waves is difficult to explain.

The vertical structure of the waves in the initial value integration extends throughout the troposphere in the middle latitudes but becomes confined to the upper troposphere as the wave train approaches the Tropics. This behavior is consistent with the basic state as the westerly duct is also confined to the upper troposphere, with mean lower-tropospheric easterlies over the tropical eastern Pacific, and a critical line in the middle troposphere. The anomalies would also be expected to become more vertically constrained from the Rossby height scale $H \sim f L / N$ as $f$ decreases toward the equator.

The divergent structure of the model waves is also very similar to observations. The region of ascent ahead of the cyclonic anomalies has an associated negative temperature anomaly and reduction in static stability. Together with a moistening of the column and reduction of convective inhibition (Juckes and Smith 2000), this would provide the means to initiate convection over the eastern tropical Pacific.

The zonal wavenumber 6-7 scale of the waves appears to be set by the basic state. Baroclinic growth upstream in the Asian jet tends to favor waves with zonal wavenumber 6 . On reaching the Pacific sector, lower-wavenumber components of the wave train are not refracted so strongly equatorward, while higherwavenumber components are advected quickly along the Pacific jet before they can propagate equatorward. Given the spatial scale of the waves, the time period of 13 days then corresponds well to that predicted by barotropic Rossby wave theory.

A barotropic model was also used to examine the wave behavior. It was linearized about the 200-hPa DJF mean flow and initialized with a localized zonal wavenumber 6 perturbation in the African-Asian jet, similar to the baroclinic model initial value integration in section 3. The subsequent dispersion of the wave train also showed cross-equatorial propagation over the eastern Pacific, in a similar manner to the baroclinic model. However, a barotropically unstable mode eventually dominated. This had a long time period of 60 days, and a spatial structure similar to the most unstable barotropic mode of Simmons et al. (1983). The $e$-folding time of approximately 1 week for the barotropic mode is slower than the $e$-folding time of approximately 5 days for the baroclinic mode in the Asian jet from section 3. Therefore, it appears that the initial structure of the waves in the Asian jet is governed by baroclinic dynamics; the waves then propagate approximately as barotropic Rossby waves over the Pacific, with a possible modification by the barotropically unstable mode.

Matthews and Kiladis (1999b) found that the equatorward propagation of the waves was sensitive to changes in the mean flow. In an initial value integration using the DJF climatological basic state from El Niño years only, the equatorward propagation of the wave train was weaker and farther east. This was attributed to the stronger continuous Asian-Pacific-North American jet and the weaker westerly duct. In the extreme 1997/98 El Niño the westerly duct almost vanished and equatorward propagation was eliminated. The weaker discontinuous jet and strengthened westerly duct of a La Niña basic state enhanced the equatorward propagation. Hence, in climate studies an essential first step in modeling the transient waves is that the time mean flow over the Pacific region is accurately simulated. This was a conclusion in the general circulation model study of Reynolds and Gelaro (1997) where the Pacific jet was too strong, with an associated reduction in the equatorward-propagating waves compared to observations.

Although the dry baroclinic wave dynamics simulate most of the features of the observed circulation, they do not account for the equatorial Rossby wave structures observed to propagate westward through the lower troposphere from the region of ITCZ convection. It has been hypothesized that these westward-propagating equatorial Rossby waves initiate subsequent convection over the western Pacific (Meehl et al. 1996; Slingo 1998) and are an important part of the regional circulation. In a separate integration, we forced the primitive 
equation model with the time-varying diabatic heating field associated with the observed ITCZ convection. The equatorial Rossby wave response to this heating simulates the observations well; hence the diabatic heating appears to be crucial for this part of the circulation.

Acknowledgments. The authors thank David Karoly, Jorgen Frederiksen, and Kathy Harris for helpful discussions and comments, and Brian Hoskins and Jake Badger for advice on balancing the initial value perturbations. The comments of two anonymous reviewers helped to improve the manuscript. The OLR and NCEPNCAR reanalysis data were provided through the NOAA Climate Diagnostics Center (http:// www.cdc.noaa.gov). This research was supported in part through the Australian Government Cooperative Research Centres Program and in part by the Pan-American Climate Studies Program, under Project GC95-820, sponsored by NOAA's Office of Global Programs.

\section{REFERENCES}

Ambrizzi, T., and B. J. Hoskins, 1997: Stationary Rossby-wave propagation in a baroclinic atmosphere. Quart. J. Roy. Meteor. Soc., 123, 919-928.

Gill, A. E., 1980: Some simple solutions for heat-induced tropical circulation. Quart. J. Roy. Meteor. Soc., 106, 447-462.

Hoskins, B. J., and A. J. Simmons, 1975: A multi-layer spectral model and the semi-implicit method. Quart. J. Roy. Meteor. Soc., 101, 637-655.

— , and D. J. Karoly, 1981: The steady linear response of a spherical atmosphere to thermal and orographic forcing. J. Atmos. Sci., 38, 1179-1196.

— , and T. Ambrizzi, 1993: Rossby wave propagation on a realistic longitudinally varying flow. J. Atmos. Sci., 50, 1661-1671.

Hsu, H.-H., and S.-H. Lin, 1992: Global teleconnections in the 250mb streamfunction field during the Northern Hemisphere winter. Mon. Wea. Rev., 120, 1169-1190.

Juckes, M., and R. K. Smith, 2000: Convective destabilisation by upper-level troughs. Quart. J. Roy. Meteor. Soc., 126, 111-124.

Kalnay, E., and Coauthors, 1996: The NCEP/NCAR 40-Year Reanalysis Project. Bull. Amer. Meteor. Soc., 77, 437-471.

Karoly, D. J., 1983: Rossby wave propagation in a barotropic atmosphere. Dyn. Atmos. Oceans, 7, 111-125.
Kiladis, G. N., 1998: An observational study of Rossby waves linked to convection over the eastern tropical Pacific. J. Atmos. Sci., $\mathbf{5 5}, 321-339$.

— and K. M. Weickmann, 1992a: Circulation anomalies associated with tropical convection during northern winter. Mon. Wea. Rev., 120, 1900-1923.

$\longrightarrow$, and $-1992 \mathrm{~b}$ : Extratropical forcing of tropical Pacific convection during northern winter. Mon. Wea. Rev., 120, 19241938.

, and S. B. Feldstein, 1994: Rossby wave propagation into the Tropics in two GFDL general circulation models. Climate Dyn., 9, 245-252.

— , and K. M. Weickmann, 1997: Horizontal structure and seasonality of large-scale circulations associated with submonthly tropical convection. Mon. Wea. Rev., 125, 1997-2013.

Liebmann, B., and C. A. Smith, 1996: Description of a complete (interpolated) OLR dataset. Bull. Amer. Meteor. Soc., 77, 12751277.

Mapes, B. E., and R. A. Houze Jr., 1995: Diabatic divergence profiles in western Pacific mesoscale convective systems. J. Atmos. Sci., 52, 1807-1828.

Matthews, A. J., and G. N. Kiladis, 1999a: The tropical-extratropical interaction between high-frequency transients and the MaddenJulian oscillation. Mon. Wea. Rev., 127, 661-677.

— culation and tropical convection over the Pacific. J. Climate, 12, 3062-3086.

Meehl, G. A., G. N. Kiladis, K. M. Weickmann, M. Wheeler, D. S. Gutzler, and G. P. Compo, 1996: Modulation of equatorial subseasonal convective episodes by tropical-extratropical interaction in the Indian and Pacific Ocean regions. J. Geophys. Res., 101, $15033-15049$.

Reynolds, C., and R. Gelaro, 1997: The effect of model bias on the equatorward propagation of extratropical waves. Mon. Wea. Rev., 125, 3249-3265.

Simmons, A. J., J. M. Wallace, and G. W. Branstator, 1983: Barotropic wave propagation and instability, and atmospheric teleconnection patterns. J. Atmos. Sci., 40, 1363-1392.

Slingo, J. M., 1998: Extratropical forcing of tropical convection in a northern winter simulation with the UGAMP GCM. Quart J. Roy. Meteor. Soc., 124, 27-52.

Tomas, R. A, and P. J. Webster, 1994: Horizontal and vertical structure of cross-equatorial wave propagation. J. Atmos. Sci., 51, 14171430.

Webster, P. J., and J. R. Holton, 1982: Cross-equatorial response to middle-latitude forcing with a latitudinally and zonally nonuniform basic state. J. Atmos. Sci., 39, 722-733.

Yang, G.-Y., and B. J. Hoskins, 1996: Propagation of Rossby waves of nonzero frequency. J. Atmos. Sci., 53, 2365-2378. 